\title{
National Perspectives on Marine Biotechnology
}

\author{
By D.H. Attaway
}

B IOTECHNOLOGY DEPENDS on exploiting information stored in genes and their component DNA. Genes of terrestrial organisms have been the primary source of information for the biochemical products and bioprocessing schemes that form the foundation of biotechnology-antibiotic production and water purification, for example. While terrestrial organisms exhibit great species diversity, marine organisms represent greater phylogenetic diversity. That is, most of the major classes of the Earth's plants, animals, and microorganisms are primarily or exclusively marine. Thus marine organisms represent sources of unique genetic information. Yet few have been used in biotechnology by either traditional methods of fermentation or modern biomolecular means because the research base is meager. However, results from programs of research in marine biotechnology, including those in Japan, are exposing rich fields of opportunity.

Hydrothermal vents associated with tectonic spreading zones in the ocean are sites particularly rich in novel organisms. "There are still $\sim 50,000 \mathrm{~km}$ of unexplored submarine tectonic spreading zones girdling the globe with several thousands of projected hydrothermal vent sites. Only $\sim 100$ of them have been visited by re-

D.H. Attaway, National Sca Grant College Program. National Oceanic and Atmospheric Administration. 1315 East-West Highway, Silver Spring. MD 20910, USA. search submersibles, and even fewer of them have been sampled. All of them appear to be different, chemically as well as biologically. It is well justified to conclude that, as a newly explored marine environment, hydrothermal vent sites promise a wealth of biotechnologically useful microorganisms." (Jannasch, 1995)

In 1992 the U.S. Government estimated its investment in research supporting the development of marine biotechnology at $\$ 44$ million in seven categories* and nine departments and agencies $\dagger$ and its investment in biotechnology research overall at $\$ 3.76$ billion (Biotechnology Research Subcommittee, 1992). In a recent report on biotechnology (Biotechnology Research Subcommittee, 1995) the National Science and Technology Council (NSTC) included marine biotechnology as one of four fields of particular significance. The NSTC report identified marine research needs and opportunities relating to aquaculture, understanding and conserving the seas, and industrial products and processes, including bioremediation and energy production. The development of marine biotechnology by both traditional

* Molecular genetics. hiomaterials, metabolic products, biofilms, bioprocessing, environment. and aquaculture.

+ Departments of Agriculture. Energy. and Navy. Environmental Protection Agency, Fish and Wildife Service. Food and Drug Administration. National Institutes of Health, National Oceanic \& Atmospheric Administration. National Science Foundation. and modern methods is just beginning. It offers enormous potential for advancing science and commerce, training students for high technology, developing a spectrum of products and processes, and improving management of oceanic resources.

Proteins that make up the framework of oyster shells have provided models for new classes of synthetic, biodegradable polymers with a range of properties useful in industry. Donlar Corporation of Bedford Park, Illinois, was established in 1990 to commercialize and further develop the results of the academic research that focused originally on determining the mechanisms by which mollusk shells form. The company is marketing new polymers for water treatment and agricultural applications and estimates potential markets in the $\$ 100$ 's of mil-

lions. University research also has identified marine compounds with powerful anti-inflammatory, antibiotic, and antitumor properties and stimulated corresponding pharmaceutical R\&D. For example, Osteoarthritis Sciences, Inc., established in 1991 in Cambridge, Massachusetts, is evaluating marine com- 
pounds as candidates for drug develop-

ment. It has identified promising model

compounds, and one will soon enter clinical trials for treatment of dermatitis. Marine organisms are providing pharmaceutical models fundamentally different from those of terrestrial organisms at a time when many human pathogens are rapidly developing resistance to standard antibacterial drugs-in part a consequence of repeatedly modifying traditional antibiotics to provide additional therapeutic agents.

The NSTC's 1995 report, Biotechnology for the 21st Century: New Horizons, identifies the following priorities (paraphrased) for research in support of marine biotechnology and aquaculture:

- Develop a fundamental understanding of the genetic, nutritional, and environmental factors controlling production of useful metabolites in marine organisms;

- Develop a fundamental information about bioactive products and biosynthetic pathways to aid in developing new biochemical products and bioma- terials, including enzymes and pharmaceuticals;

- Explore and define metabolic processes of marine organisms and corresponding strategies for application in bioremediation and bioprocessing;

- Use tools of biotechnology to improve the health, reproduction, and growth of cultivated aquatic organisms and promote interdisciplinary efforts to develop environmentally benign production systems: and

- Develop a fuller understanding of the physiology, genetics, biochemistry, and ecology of marine microbes for exploiting their biological products and processes and for improving knowledge of oceanic processes and conservation of oceanic resources.

The federal investment in research supporting marine biotechnology has grown by about $\$ 10$ million since 1992 to around $\$ 55$ million. Much of the new federal effort in marine biotechnology since 1992 has been in programs of the Ocean Margins Program of the Department of Energy (DOE) and the Department of Commerce's National Sea Grant College Program in the National Oceanic and Atmospheric Administration. Corresponding research in most other federal agencies has paced inflation. The National Institutes of Health still make the greatest federal investment in this field-to a major degree in developing drugs to fight cancer and AIDS. With its new funds DOE is applying molecular biological techniques to defining processes controlling atmo- spheric carbon dioxide and to sequencing genomes of environmentally significant microorganisms. Sea Grant's expanded research program addresses policy and environmental issues, new biomaterials and products, bioprocessing, molecular genetics, and aquaculture.

The U.S. Congress, the NSTC, several federal departments and agencies, and representatives of academe and industry have recognized the opportunities for exploiting the genetic resources of aquatic organisms to provide commercial products and processes, to stimulate economic development, to develop tools for resource management, and to define global changes that are affected by metabolic processes. In doing so, the United States is helping lead a worldwide effort in marine biotechnology that will advance human well-being.

\section{References}

Biotechnology Research Subcommittee. 1992: Biotechnology for the 2Ist Century. A report for the Committee on Life Sciences and Health of the Federal Coordinating Council for Science, Engineering and Technology, U.S. Government Printing Office. Washington. DC 20402-9328, 58

Biotechnology Research Subcommittee, 1995 Biotechnology for the 21st Century: New Horizons. A report for the Committee on Fundamental Science of the National Science and Technology Council, U.S. Government Printing Office, Washington. DC 20402-9328, 47-61

Jannasch. H.W., 1995: Deep-sea hot vents as sources of biotechnologically relevant microorganisms. J. Mar. Biotechnol., 3, 5-8. 